\title{
Residual Distribution and Risk Assessment of Polychlorinated Biphenyls in Surface Sediments of the Pearl River Delta, South China
}

\author{
Zini Lai ${ }^{1} \cdot$ Xiuli $\mathrm{Li}^{1,2} \cdot$ Haiyan $\mathrm{Li}^{1} \cdot \operatorname{Lina} \mathrm{Zhao}^{1,2}$. \\ Yanyi Zeng ${ }^{1}$ Chao Wang ${ }^{1} \cdot$ Yuan Gao $^{1} \cdot$ Qianfu Liu $^{1}$
}

Received: 27 December 2013/Accepted: 19 May 2015/Published online: 28 May 2015

(C) The Author(s) 2015. This article is published with open access at Springerlink.com

\begin{abstract}
We analyzed residual PCBs in surface sediments at 19 sites in the Pearl River Delta in the wet and dry seasons. Seven indicative PCB congeners (PCB28, PCB52, PCB101, PCB118, PCB153, PCB138 and PCB180) were detected in the surface sediments, among which the detection rate and mass concentrations of PCB52 were the highest. Total concentrations of the seven PCBs ranged from 19.8 to $111 \mu \mathrm{g} /$ $\mathrm{kg}$, with an average of $48.2 \mu \mathrm{g} / \mathrm{kg}$. For the spatial distribution, the sum of the seven PCB ( $\sum$ PCB) concentrations for the stations that were located in the city region of the Pearl River Delta were significantly higher than the $\sum$ PCB concentrations for the eight outlets of the Pearl River Delta $(p<0.05)$. According to the US National Oceanic and Atmospheric Administration ERL and ERM guideline concentrations, the PCB concentrations may occasionally lead to adverse effects, especially in the dry season.
\end{abstract}

Keywords Pearl River Delta $\cdot$ PCBs $\cdot$ Surface sediments · Risk assessment

Polychlorinated biphenyls (PCBs) are a group of 209 different chemicals considered to be pollutants of environmental and human health concern. Although PCBs are now ubiquitous in the environment, they have resulted from industrial production without any known natural source.

Zini Lai

znlai01@163.com

1 Pearl River Fisheries Research Institute, Chinese Academy of Fishery Sciences, Fishery Ecoenvironment Monitor and Evaluation Function Laboratory of Pearl River Valley, Guangzhou 510380, China

2 Shanghai Ocean University, College of Aquatic and Life, Shanghai 201306, China
Atmospheric transport and deposition, current transport, riverine input, sea-ice transport and biotic transport are considered to be the main sources (Macdonald et al. 2000; AMAP 2004). PCBs were widely used in many manufacturing processes between the 1930s and 1970s, and their production rose quickly, reaching $2.1 \times 10^{6}$ t to satisfy worldwide demand. It is reported that approximately 10000t of PCBs were produced from 1965 to the early 1980s in China, accounting for about $1 \%$ of global production (Zheng et al. 2010). Although the production of PCBs has been banned since the early 1970s in many countries, residuals can still be found in the environment (Harrad et al. 1994; Sprovieri et al. 2007). PCBs persist as legacy pollutants for which chronic toxicity still represents a serious environmental risk due to their stability and permanence (Wang et al. 2011; Konat et al. 2001).

The Pearl River Delta (PRD) is located on the southeast coast of China. It is one of the most developed regions and also the second most populous area in China, resulting in environmental pollution that may affect the health of the population in the region. Electronics, electrical machines, and petrochemicals dominate the local industrial structure, cumulatively accounting for over $50 \%$ of the local industry. The urbanized and industrialized processes in the region, especially from electrical factory industrial activities were assumed to be the main sources of PCBs (Kang et al. 2000; Mai et al. 2005; Nie et al. 2005, 2006). PCB contamination in the region was mainly concentrated in the sediment and water (Yang et al. 1997; Kang et al. 2000; Mai et al. 2005;). Numberous studies have investigated the occurrence of PCBs in various compartments of the PRD (Nie et al. 2005; Wang et al. 2011; Zhang et al. 2013; Guan et al. 2009).

The Global Environment Monitoring System - Food Contamination Monitoring and Assessment Programme 
(GEMS/Food) stipulate PCB28, PCB52, PCB101, PCB118, PCB138, PCB153 and PCB180 as indicator PCBs to indicate PCBs pollution status. Zhang et al. (2013) reported that six of these PCBs (PCB28, 52, 101, 118, 138, and 153) were detected in most surface soil samples in the PRD. The present study covers the whole Pearl River watershed (19 sites), while other papers focus on just one part of the watershed. The distribution of the seven indicator PCBs was determined in recent sediments from the PRD in this study. The present study aimed to assess the current contamination level and evaluate the temporal variation that occurred over the decades. The composition and distribution of the PCBs was investigated, and a pollution risk assessment was undertaken. Basic information for the potential hazard assessment of PCBs in the PRD coastal environment was obtained during this study.

\section{Materials and Methods}

Thirty-eight samples of surface sediments from 19 sites (Fig. 1) were collected (March 19th, 2012 and August 19th, 2012) from the PRD in south China. The two sampling periods were defined as the wet and dry seasons, respectively. Eleven of the 19 sampling sites (S1-S11) were located in the city region of the PRD, with the other eight sites (S12-S19) being in the outlets of the PRD. The surface sediments were collected with a grab-type sampler, placed into pre-cleaned amber bottles, and stored at $-20^{\circ} \mathrm{C}$ prior to analysis.

All the sediment samples from the same site were mixed, freeze-dried, and homogenized by grinding. Firstly, eachmixed sample $(5 \mathrm{~g})$ was treated with $40 \mathrm{~mL}$ of hexane- acetone $(1: 1, \mathrm{v} / \mathrm{v})$ for $12 \mathrm{~h}$ in a $100 \mathrm{~mL}$ colorimetric tube with a stopper. Next, all samples were sonicated for $20 \mathrm{~min}$. Then, the extracts were decanted, and the remainder resonicated with $20 \mathrm{~mL}$ of hexane for $20 \mathrm{~min}$ (repeated three times). After resonicating, the four extracts were mixed together and treated with activated copper, to remove sulfates. The mixture was then concentrated to $5.0 \mathrm{~mL}$ by a rotary evaporator. Next, a separatory funnel was used to remove the extract. Concentrated sulfuric acid $(30 \mathrm{~mL}, 98 \%$, AR) was added to remove impurities; this was repeated if the extract remained coloured. Ultrapure water $(100 \mathrm{~mL})$ was then used to wash the organic phase twice, and the washed organic phase was purified with $5 \mathrm{~g}$ of anhydrous sodium sulfate (heated at $550^{\circ} \mathrm{C}$ for $4 \mathrm{~h}$ prior to use). Finally, the sample was concentrated to $1 \mathrm{~mL}$ for analysis (Fig. 2).

PCB congeners were analyzed by electron capture gas chromatography (Aglient 6890, Aglient Technologies, Santa Clara, CA, USA). Separations were carried out using an HP5 quartz capillary column $(30 \mathrm{~m} \times 0.32 \mathrm{~mm} \times 0.25 \mu \mathrm{m})$. Nitrogen (99.99\% pure) was used as the carrier gas at a constant flow of $1 \mathrm{~mL} / \mathrm{min}$. The oven temperature was initially $150^{\circ} \mathrm{C}$, held for $1 \mathrm{~min}$, and was increased to $200^{\circ} \mathrm{C}$ at a rate of $10^{\circ} \mathrm{C} / \mathrm{min}$, maintained for $1.0 \mathrm{~min}$, and then raised to $260^{\circ} \mathrm{C}$ at a rate of $5^{\circ} \mathrm{C} / \mathrm{min}$, and held for $1 \mathrm{~min}$. The injection was at $250^{\circ} \mathrm{C}$ in splitless mode, and the detector was at $300^{\circ} \mathrm{C}$.

A total organic carbon (TOC) analysis was conducted using the National Environmental Protection Standard's spectrophotometric method (HJ615-2011) for soil-determination of organic carbon-potassium dichromate oxidation.

Strict quality control procedures were implemented throughout the entire process. For every set of 10 samples, procedural blanks, spiked blanks (standards spiked into

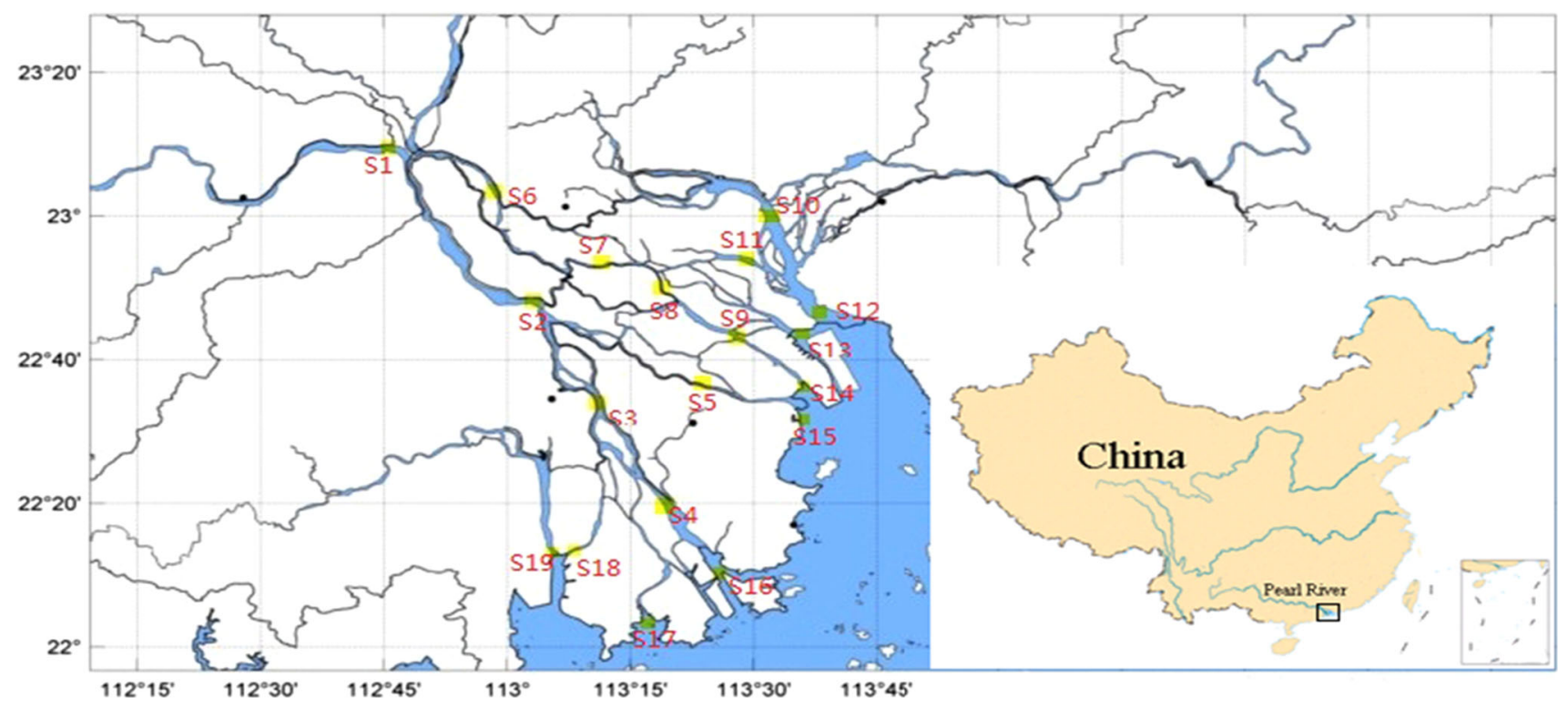

Fig. 1 Distribution of the sampling sites in the Pearl River Delta 
Fig. 2 Principal component plot of PCBs in the Pearl River Delta

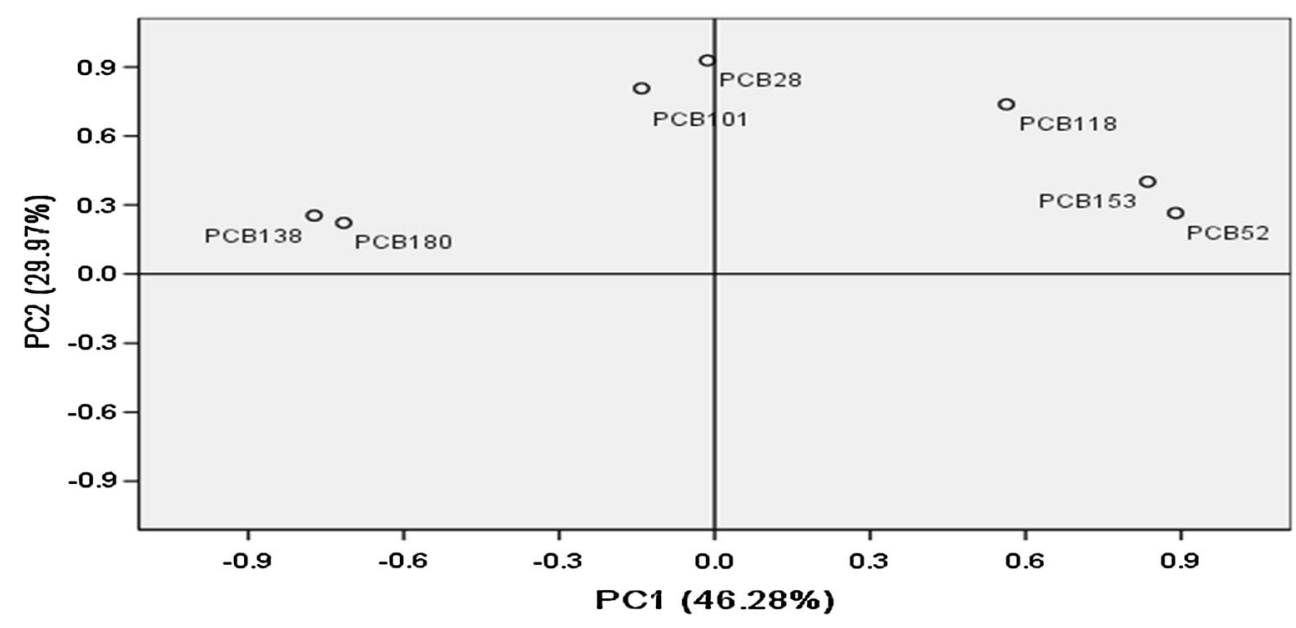

solvent), matrix spikes/matrix spike duplicates, and sample duplicates were processed. The spiked recovery for PCB congeners in the sediments ranged from $80.9 \%$ to $113.2 \%$. The instrumental limit of detection (LOD) was determined as the concentration of analytes that gave rise to a peak with a signal-to-noise ratio $(\mathrm{S} / \mathrm{N})$ of 3 , and ranged from 0.01 to $0.06 \mu \mathrm{g} / \mathrm{kg}$ for the different PCB congeners. All the data were corrected with the recovery rates and reported in $\mu \mathrm{g} / \mathrm{kg} \mathrm{dw}$ (dry weight).

The $\sum \mathrm{PCB}$ concentration was defined as the sum of seven PCB congeners (PCB28, PCB52, PCB101, PCB118, PCB138, PCB153 and PCB180). Data analyses were performed using SPSS 14.0 (SPSS Inc., Chicago, 1L, USA). Multiple comparisons were conducted with Tukey's honestly significant difference (HSD) test using ANOVA. Differences were considered to be significant if $p<0.05$.

\section{Results and Discussion}

As shown in Table 1, the seven indicative PCB congeners had different detection rates in the sediment samples from the PRD in the wet and dry periods. The $\sum$ PCB concentrations in the sediments ranged from 19.8 to $111 \mu \mathrm{g} / \mathrm{kg}$, with an average of $48.3 \mu \mathrm{g} / \mathrm{kg}$. The detection rate and concentrations of PCB52 were the highest: the detection rate of PCB52 was $100 \%$, followed by PCB180, with a detection rate of $97.4 \%$; the concentration of each PCB congener was in the order PCB52 $>$ PCB118 $>$ PCB $101>$ PCB153 > PCB28 > PCB138 > PCB180.

Studies have shown that incinerators and processes using chloride oxidation (e.g. paper bleaching or de-inking technology) discharge predominantly less-chlorinated PCBs (Krauss and Wilcke 2001); however, the pollutants in transformer oil have more highly chlorinated PCBs (Takasuga et al. 2006). The concentrations of less-chlorinated PCBs were higher than those of highly chlorinated PCBs in the sediment samples from the PRD in the two periods. The tetra-PCB content accounted for the largest proportion of the total amount of sediment PCBs, at $56 \%$. This implies that the PCBs in the PRD may be related to the wastewater from nearby paper mills and dyeing and weaving works; and perhaps also because highly chlorinated PCBs could be decomposed to less-chlorinated PCBs by bacteria, fungi and other microorganisms. However, an additional explanation may be that the major PCB congeners discharged into the environment in China were tri-PCBs to hexa-PCBs and comprised $80 \%$ of the total PCB production. Furthermore, it is easier for less-chlorinated congeners to be transported over long distances (Wu et al. 2011).
Table 1 Concentrations of PCBs in surface sediments from the Pearl River Delta

\begin{tabular}{llccc}
\hline PCB & $\begin{array}{l}\text { Number of } \\
\text { chlorine atoms }\end{array}$ & $\begin{array}{l}\text { Range } \\
(\mu \mathrm{g} / \mathrm{kg})\end{array}$ & $\begin{array}{l}\text { Average } \\
(\mu \mathrm{g} / \mathrm{kg})\end{array}$ & $\begin{array}{l}\text { Detection } \\
\text { rate }(\%)\end{array}$ \\
\hline PCB28 & 3 & ND-14.5 & 2.65 & 52.6 \\
PCB52 & 4 & $9.90-53.2$ & 27.2 & 100 \\
PCB101 & 5 & ND-13.2 & 3.54 & 65.8 \\
PCB118 & 5 & ND-32.7 & 7.05 & 81.6 \\
PCB138 & 6 & ND-15.1 & 2.46 & 71.1 \\
PCB153 & 6 & ND-15.0 & 3.33 & 89.5 \\
PCB180 & 7 & ND-11.4 & 1.96 & 97.4 \\
\hline
\end{tabular}

$N D$ not detected 
The distribution of PCBs in the PRD sediments, with concentrations of highly chlorinated PCBs relatively low in the study area, is in accord with many other studies (Shen et al. 2006; Chen et al. 2009; Ji et al. 2009). Guan et al. (2009) studied PCBs in riverine runoff of the PRD, and found that tri- to penta-PCBs accounted for approximately $90 \%$ of total PCBs. No octa- to deca-PCBs were detected. Chen and colleagues (1999) analyzed sediment samples for 14 PCB congeners from 22 rivers in east China, and found PCB52, PCB101, PCB87 and PCB149 (i.e., tetra-, pentaand hexa-PCBs) to have the highest concentrations, accounting for $50 \%$ of the PCBs. Zhang et al. (2013) analyzed PCB contamination in soils of the PRD, finding that PCBs were dominated by low-chlorinated biphenyls; however, the pro-portion of higher-chlorinated biphenyls was elevated with the influence of industrial activities.

Concentrations of $\sum$ PCBs and TOC in August in surface sediments from the PRD are shown in Table 2. A correlation analysis between the $\sum$ PCBs concentrations and TOC at each site revealed significant correlation $(\mathrm{r}=0.550, p<0.05)$. The findings were consistent with a previous study which indicated that higher concentrations of PCBs typically occur in sediments having a larger fraction of clays, OM, or micro-particulate matter (Burgess et al. 2001), but not consistent with another study which found that $\sum$ PCBs concentrations did not significantly correlated with their geochemical parameters (including sediment carbon) (Wang et al. 2011).

Table 2 Concentrations of $\sum$ PCBs and TOC in August in surface sediments from the Pearl River Delta

\begin{tabular}{lll}
\hline Stations & $\sum$ PCBs $(\mu \mathrm{g} / \mathrm{kg})$ & TOC $(\%)$ \\
\hline S1 & 45 & 1.96 \\
S2 & 35.2 & 2.28 \\
S3 & 44.6 & 2.03 \\
S4 & 37.3 & 2.32 \\
S5 & 48.5 & 1.34 \\
S6 & 67.6 & 1.34 \\
S7 & 48.2 & 1.81 \\
S8 & 85.5 & 2.04 \\
S9 & 47 & 1.49 \\
S10 & 94.1 & 1.24 \\
S11 & 48.1 & 1.60 \\
S12 & 42.9 & 2.16 \\
S13 & 30.7 & 2.14 \\
S14 & 34.7 & 2.56 \\
S15 & 29.5 & 2.76 \\
S16 & 35.7 & 2.00 \\
S17 & 23.9 & 2.00 \\
S18 & 29.9 & 1.68 \\
S19 & 37.4 & 1.98 \\
\hline
\end{tabular}

The first two principal components (PCs) were extracted by $\mathrm{PCA}$, relating to $46.3 \%$ and $30.0 \%$ of the total variance, respectively. $\mathrm{PCB} 52, \mathrm{PCB} 118$ and $\mathrm{PCB} 153$ were grouped together, indicating that they had a similar nature, and might have the same source. In addition, PCB28 was near PCB101, indicating that both $\mathrm{PCBs}$ might originate from similar sources; the same applies to PCB138 and PCB180. Analysis showed $(n=19)$ no correlation between the seven indicative PCBs and the organic matter in sediments. No apparent co-relationships between PCB concentrations and sediment properties were obtained, indicating that the distribution of PCBs was controlled not only by their source but also by multiple factors such as atmospheric transport and deposition, mixing, partitioning and sorption in the water column and sediments (Hong et al. 2012).

The lowest $\sum$ PCB concentrations were detected at site S17 in both the wet and dry seasons; and, combined for both seasons, the highest $\sum$ PCB concentrations were for site S10 (Fig. 3). The $\sum$ PCB concentrations for the sites located in the city region of the PRD (S1-S11) were significantly higher than the $\sum \mathrm{PCB}$ concentrations for the eight outlets of the PRD (S12-S19) $(p<0.05)$. However, there were no significant differences between the $\sum \mathrm{PCB}$ concentrations for the eight outlets of the PRD (S12-S19) $(p>0.05)$. The highest $\sum \mathrm{PCB}$ concentrations were for site S10, mainly because most of the domestic and industrial wastewater from the cities of Guangzhou and Dongguan enter the South China Sea at site S10. According to official statistics, there were more than 230 sewage treatment plants in Guangdong province at the end of 2009, disposing of approximately $13 \times 10^{6} \mathrm{t}$ sewage every day. The sewage from the nine cities in the PRD accounted for about $90 \%$ of the total wastewater of Guangdong province. PCBs in water can sink downward into the sediments after a time; therefore, the sewage treatment plants might be the cause of the higher concentrations of PCBs in the city region of the PRD (S1-S11). Additionally, during the operation of the port and shipping, the emission of toxic liquid waste, solid rubbish and fuel oil increased the pollution load of PCBs in the sediments. The $\sum$ PCB concentrations for the eight outlets of the PRD (S12-S19) were relatively low, which may be because the eight outlets accepted not only a huge pollution from the Pearl River stream but also a large quantity of water from the South China Sea that was less contaminated, so that the $\sum$ PCB concentration could be diluted in the water.

It has been reported that PCBs in the soil at the scrap capacitor sealing point in Yangjiang city in Guangdong province were mainly tetra-PCBs, and that their composition was similar to Aroclor 1248 (Chen et al. 2008). A similar composition in the Pearl River reach sediment column has also been observed (Mai et al. 2005), 

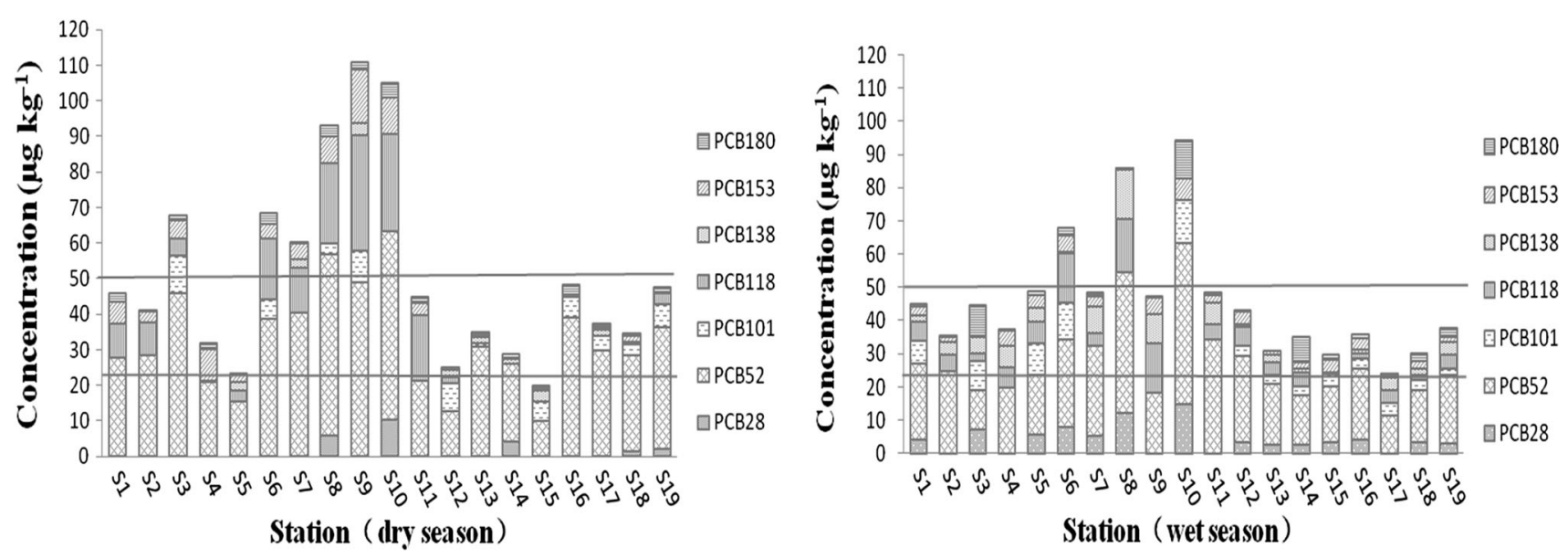

Fig. 3 Concentrations of the individual PCB homologues in the wet and dry seasons. (The two lines represnt the ERL and the concentration of $50 \mu \mathrm{g} / \mathrm{kg} \mathrm{dw}$, respectively)

suggesting that imported capacitors may account for a certain proportion of capacitive devices in the PRD, and that the release of PCBs from these components influenced PCB composition in the PRD. The cluster analysis for samples from the 19 sites in this study showed that they had similar compositions, indicating that they may have the same sources, and may be the result of pollution by the same products. However, the influence of many changes that have occurred in the environment cannot be excluded.

The $\sum$ PCB concentrations in the sediments ranged from 19.8 to $111 \mu \mathrm{g} / \mathrm{kg}$, with an average of $48.2 \mu \mathrm{g} / \mathrm{kg}$. Compared to other areas around the world (Table 3), the $\sum$ PCB concentrations in the PRD were in the mid-range (Yang et al. 2009; Wu et al. 2011).

Table 3 Concentrations of PCBs in surface sediment samples and other reported studies

\begin{tabular}{|c|c|c|c|c|c|}
\hline Location & $\mathrm{n}$ & Range $(\mu \mathrm{g} / \mathrm{kg} \mathrm{dw})$ & Average $(\mu \mathrm{g} / \mathrm{kg} \mathrm{dw})$ & Year & References \\
\hline Pearl River Estuary, China & 128 & $11.5-485$ & - & 1997 & Kang et al. (2000) \\
\hline Hong Kong coast & & $0.1-461$ & 52.2 & - & Wong et al. (2000) \\
\hline Pearl River Estuary, China & 25 & $10-303$ & & 1997 & Mai et al. (2002) \\
\hline Daya Bay & 12 & $0.85-27.4$ & 8.83 & 1999 & Zhou et al. (2001) \\
\hline New Brunswick, Canada & 132 & $1.07-10.4$ & - & 1988 & Sather et al. (2006) \\
\hline Pearl River Estuary, China & 37 & $5.10-11.0$ & 7.96 & 2009 & Wang et al. (2011) \\
\hline Pearl River Estuary, China & 36 & $11.1-23.2$ & & 2000 & Nie et al. (2005) \\
\hline Fu River, China & 12 & $4.2-198$ & 46.3 & 2008 & Hu et al. (2010) \\
\hline Fenhe Reservoir and Watershed, China & 123 & ND-126.5 & 27.3 & 2010 & Li et al. (2012) \\
\hline Haihe River, China & 32 & ND-253 & 66.8 & 2007 & Zhao et al. (2010) \\
\hline Dianchi Lake, China & 6 & $0.6-2.4$ & 1.2 & 2008 & Wan et al. (2011) \\
\hline $\begin{array}{l}\text { The mid- and downstream of the } \\
\text { Yellow River, north China }\end{array}$ & - & ND-6.0 & 3.1 & 2004 & He et al. (2006) \\
\hline Wuhan reach of the Yangtze River, China & 39 & $1.2-45.1$ & 9.2 & 2005 & Yang et al. (2009) \\
\hline Donggang River, Taiwan & 121 & $25.5-63.5$ & - & 2003-2004 & Hsieh et al. (2011) \\
\hline Lake Michigan, USA & 163 & $53-35,000$ & 7400 & 2006 & Martinez et al. (2010) \\
\hline Bering Sea & 14 & $22-150$ & 71 & - & Wang et al. (2012) \\
\hline Chukchi Sea & 14 & $60-640$ & 190 & 2008 & Hong et al. (2012) \\
\hline Canada Basin & 14 & $24-600$ & 150 & - & Wang et al. (2012) \\
\hline Pearl River Delta, China & 7 & $19.8-111$ & 48.2 & 2012 & This study \\
\hline
\end{tabular}

$N D$ not detected 
As Fig. 3 shows, the $\sum$ PCB concentrations in the wet season were higher than in the dry season, but not significantly $(p>0.05)$. Precipitation and pollution sources are considered to be the main factors causing fluctuations in water quality. The temporal variations in the PCBs in the two periods might be caused mainly by the difference in the amount of precipitation in these two periods ( $\mathrm{Li}$ et al. 2012). In the wet season, the grain size composition of sediments changed from clay to sand owing to the floods and heavy rains. As a result, the organic matter content in sediments was reduced, so that the content of PCBs in the sediments also decreased. However, in the dry season, with less precipitation and surface runoff, $\mathrm{PCBs}$ in the water were deposited in the sediments, and the PCB content of the sediments thus increased.

Considering the toxicity and bioaccumulation property of PCBs, as well as the Pearl River being a major source of water for irrigation and aquaculture, it is of particular interest to evaluate the potential risk of PCBs in sediments of the Pearl River. So far, there is still no uniform standard available to assess the biological effects of PCBs, but several studies have been carried out, and some useful indicators have been provided. Hakanson (1980) established a potential ecological risk index in which the concentration of PCBs is one of the main parameters. The US Environmental Protection Agency and the National Oceanic and Atmospheric Administration (NOAA) have established threshold (TEC) and extreme (EEC) effect concentration sediment quality guidelines (SQGs) for marine sediments (Long et al. 1995; Gomez-Gutierrez et al. 2007). The NOAA guidelines specify the 'effects range low' (ERL) and the 'effects range median' (ERM), with the ERL $(22.7 \mu \mathrm{g} / \mathrm{kg} \mathrm{dw})$ representing the chemical concentration below which adverse effects would rarely be observed, and the ERM $(180 \mu \mathrm{g} / \mathrm{kg} \mathrm{dw})$ representing the concentration above which adverse effects would frequently occur. According to Long et al. (1995), the ERL and ERM relate to seven PCB congeners (PCB28, PCB52, PCB101, PCB118, PCB138, PCB153 and PCB180), and $\sum P C B$ concentrations of more than $50 \mu \mathrm{g} / \mathrm{kg} \mathrm{dw}$ indicate moderate to severe pollution (Guo et al. 2011).

For PCBs in sediments of the PRD, the average $\sum$ PCB concentration was higher than the ERL but lower than the ERM in both the wet and dry seasons. This suggests that PCBs might cause adverse biological effects on occasion. However, the $\sum$ PCB concentration was more than $50 \mu \mathrm{g}$ / $\mathrm{kg} \mathrm{dw}$ in the dry season, indicating that the PRD suffered from moderate to severe pollution in the dry season. Regarding the $\sum \mathrm{PCB}$ concentration at each site in the two periods, comparisons of the $\sum \mathrm{PCB}$ concentration with the ERL $(22.7 \mu \mathrm{g} / \mathrm{kg} \mathrm{dw})$ can be found in Fig. 3. The ERM $(180 \mu \mathrm{g} / \mathrm{kg} \mathrm{dw})$ is not shown in Fig. 3. All 19 sites had higher concentrations than the ERL but lower than the ERM in both the wet and dry seasons, except for site S15, which had a lower concentration than the ERL in the dry season. Of the total of 19 sites, $15.8 \%$ had a $\sum$ PCB concentration greater than $50 \mu \mathrm{g} / \mathrm{kg}$ in the wet season, and $31.6 \%$ had $\sum$ PCB concentrations greater than $50 \mu \mathrm{g} / \mathrm{kg}$ in the dry season. These findings could indicate that PCBs in the sediments of the PRD might lead to occasional adverse effects, especially in the dry season.

We evaluated the concentration, composition and spatial distributions of PCBs in the surface sediments of the PRD. In conclusion, the $\sum \mathrm{PCB}$ concentrations in the sediments of the investigated area were in the mid-range compared with other areas of China and other countries. In terms of the distribution of different chlorinated PCBs, tetra-PCBs congener (PCB52) was dominant. Regarding the spatial distribution, $\sum \mathrm{PCB}$ concentrations for sites located in the city region of the PRD were significantly higher than concentrations for the eight outlets of the PRD ( $p<0.05)$. Considering temporal variation, $\sum \mathrm{PCB}$ concentrations in the dry season were higher than those in the wet season. In addition, no apparent co-relationships between concentrations of individual PCB congeners and sediment properties were obtained. However, a significant correlation was obtained for the $\sum$ PCB abd TOC during the dry season. Comparison of the measured PCB concentrations to ERL and ERM guidelines indicated that PCBs in the sediments of the investigated area may occasionally lead to adverse effects, especially in the dry season. Therefore, it is important to control PCB contamination in sediments in the PRD.

Open Access This article is distributed under the terms of the Creative Commons Attribution 4.0 International License (http://creativecommons.org/licenses/by/4.0/), which permits unrestricted use, distribution, and reproduction in any medium, provided you give appropriate credit to the original author(s) and the source, provide a link to the Creative Commons license, and indicate if changes were made.

\section{References}

AMAP (2004) AMAP assessment 2002: persistent organic pollutants in the Arctic. In: Wilson SJ, Packman G (eds) Arctic monitoring and assessment programme (AMAP). Oslo, Norway

Burgess RM, Ryba SA, Cantwell MG, Gundersen JL (2001) Exploratory analysis of the effects of particulate characteristics on the variation in partitioning of nonpolar organic contaminants to marine sediments. Water Res 35:4390-4404

Chen J, Gao X, Qi M, Blunt J (1999) The contents of polychlorinated biphenyl in river sediments in eastern China. Acta Sci Cumst 19:614-618

Chen L, Cai X, Huang Y, Xu Z, Peng X, Zhang X, Mai B (2008) Concentration and distribution of PCBs in one storage site of used capacitors. China Environ Sci 28:833-837

Chen Y, Yin Y, Wang X, Guo H, Chen S, Mai B (2009) Polycyclic aromatic hydrocarbons and polychlorinated biphenyl in surface sediments of Tai Lake: the distribution, sources and risk assessment. China Environ Sci 29:118-124

China's State Environmental Protection Administration (CEPA) (2011) Soil-determination of organic carbon-potassium 
dichromate oxidation spectrophotometric method. HJ615, Beijing, China

Gomez-Gutierrez A, Garnacho E, Bayona JM, Albaiges J (2007) Screening ecological risk assessment of persistent organic pollutants in Mediterranean sea sediments. Environ Int 33:867-876

Guan YF, Wang JZ, Ni HG, Zeng EY (2009) Organochlorine pesticides and polychlorinated biphenyls in riverine runoff of the Pearl River Delta, China: assessment of mass loading, input source and environmental fate. Environ Pollut 157:618-624

Guo JH, Yin YF, Han B, Ma YX, Yang DF, Wang XR (2011) The determination methods and the exploring to the distributional characteristics of PCBs in surface sediments of Laizhou Bay. Environ Monit China 27(3):35-41 (in Chinese)

Hakanson L (1980) An ecological risk index for aquatic pollution control: a sediment ecological approach. Water Res 14:9751001

Harrad SJ, Sewart AP, Alcock R, Boumphrey R, Burnett V, DuarteDavidson R, Halsall C, Sanders G, Waterhouse K, Wild SR, Jones KC (1994) Polychlorinated biphenyls (PCBs) in the British environment: sinks, sources and temporal trends. Environ Pollut 85:131-146

He MC, Sun Y, Li XR, Yang ZW (2006) Distribution patterns of nitrobenzenes and polychlorinated biphenyls in water, suspended particulate matter and sediment from mid- and down-stream of the Yellow River (China). Chemosphere 65:365-374

Hong QQ, Wang Y, Luo X, Chen S, Chen J, Cai M, Mai B (2012) Occurrence of polychlorinated biphenyls (PCBs) together with sediment properties in the surface sediments of the Bering Sea, Chukchi Sea and Canada Basin. Chemosphere 88:1340-1345

Hsieh CY, Lee CL, Kuo WC, Chen TC, Wang Y, Yu BY (2011) PCBs in Donggang River watershed sediments. Taiwan $\mathrm{J}$ Environ Sci Health A 46:480-489

Hu G, Luo X, Li F, Dai J, Guo J, Chen S, Hong C, Mai B, Xua M (2010) Organochlorine compounds and polycyclic aromatic hydrocarbons in surface sediment from Baiyangdian Lake, North China: concentrations, sources profiles and potential risk. J Environ Sci 22:176-183

Ji Y, Lu G, Wu H, Qin J (2009) The distribution and risk assessment of polychlorinated biphenyl in surface sediments in the northern of Tai Lake. Ecol Environ Sci 18:839-843

Kang YH, Sheng GY, Fu JM, Mai BX, Zhang G, Lin Z, Min YS (2000) Polychlorinated biphenyls in surface sediments from the Pearl River Delta and Macau. Mar Pollut Bull 40:794-797

Konat J, Kowalewska G (2001) Polychlorinated biphenyls PCBs in sediments of the southern Baltic Sea-trends and fate. Sci Total Environ 280:1-15

Krauss M, Wilcke W (2001) Predicting soil-water partitioning of polycyclic aromatic hydrocarbons and polychlorinated biphenyls by desorption with methanol-water mixtures at different temperatures. Environ Sci Technol 35:2319-2325

Li WH, Tian YZ, Shi GL, Guo CS, Feng YC, Yue XP (2012) Source and risk assessment of PCBs in sediments of Fenhe reservoir and watershed. China J Environ Monit 14:1256-1263

Long ER, Macdonald DD, Smith SL, Calder FD (1995) Incidence of adverse biological effects within ranges of chemical concentrations in marine and estuarine sediments. Environ Manag 19:81-97

Macdonald RW, Barrie LA, Bidleman TF, Diamond ML, GregorD J, Semkin RG, Strachan WMJ, Li YF, Wania F, Alaee M et al (2000) Contaminants in the Canadian Arctic: 5 years of progress in understanding sources, occurrence and pathways. Sci Total Environ 254:93-234
Mai BX, Fu JM, Sheng GY, Kang YH, Lin Z, Zhang G, Min YS, Zeng EY (2002) Chlorinated and polycyclic aromatic hydrocarbons in riverine and estuarine sediments from Pearl River Delta. China Environ Pollut 117:457-474

Mai BX, Zeng EY, Luo X, Yang Q, Zhang G, Li X, Sheng G, Fu J (2005) Abundances, depositional fluxes, and homologue patterns of polychlorinated biphenyls in dated sediment cores from the Pearl River Delta. China Environ Sci Technol 39:49-56

Martinez A, Norström K, Wang K, Hornbuckle KC (2010) Polychlorinated biphenyls in the surficial sediment of Indiana Harbor and Ship Canal, Lake Michigan. Environ Int 36:849-854

Nie XP, Lan CY, Wei TL, Yang YF (2005) Distribution of polychlorinated biphenyls in the water, sediment and fish from the Pearl River estuary. China Mar Pollut Bull 50:537-546

Nie XP, Lan CY, An TC, Li KB, Wong MH (2006) Distributions and congener patterns of PCBs in fish from major aquaculture areas in the Pearl River Delta, South China. Hum Ecol Risk Assess 12:363-373

Sather PJ, Ikonomou MG, Haya K (2006) Occurrence of persistent organic pollutants in sediments collected near fish farm sites. Aquaculture 254:234-247

Shen M, Yu YJ, Zheng GJ, Yu H, Lam PK, Feng J, Wei Z (2006) Polychlorinated biphenyls and polybrominated diphenyl ethers in surface sediments from the Yangtze River Delta. Mar Pollut Bull 52:1299-1399

Sprovieri M, Feo ML, Prevedello L, Manta DS, Sammartino S, Tamburrino S, Maeswlla E (2007) Heavy metals, polycyclic aromatic hydrocarbons and polychlorinated biphenyls in surface sediments of the Naples Harbor (southern Italy). Chemosphere 67:998-1009

Takasuga T, Senthilkumar K, Matsumura T, Shiozaki K, Sakai S (2006) Isotope dilution analysis of polychlorinated biphenyls (PCBs) in transformer oil and global commercial PCB formulations by high resolution gas chromatography-high resolution mass spectrometry. Chemosphere 62(3):469-484

Wan X, Pan X, Wang B, Zhao S, Hu P, Li F, Boulanger B (2011) Distributions, historical trends, and source investigation of polychlorinated biphenyls in Dianchi Lake, China. Chemosphere 85:361-367

Wang HS, Du J, Leung HM, Oi Wah Leung A, Liang P, Giesy JP, Wong CKC, Wong MH (2011) Distribution and source apportionment of polychlorinated biphenyls (PCBs) in mariculture sediments from the Pearl River Delta, South China. Mar Pollut Bull 63:516-522

Wong CKC, Yeyng HY, Cheung RYH, Yung KKL, Wong MH (2000) Ecotoxicological assessment of persistent organic and heavy metal contamination in Hong Kong coastal sediment. Arch Environ Contam Toxicol 38:486-493

Wu S, Xia X, Yang L, Liu H (2011) Distribution, source and risk assessment of polychlorinated biphenyls (PCBs) in urban soils of Beijing, China. Chemosphere 82:732-738

Yang YH, Sheng GY, Fu JM, Min YS (1997) Organo chlorinated compounds in waters of the Pearl River Delta region. Environ Monit Assess 44:569-575

Yang Z, Shen Z, Gao F, Tang Z, Niu J (2009) Occurrence and possible sources of polychlorinated biphenyls in surface sediments from the Wuhan reach of the Yangtze River, China. Chemosphere 74:1522-1530

Zhang HB, Luo YM, Teng Y, Wan HF (2013) PCB contamination in soils of the Pearl River Delta, South China: levels, sources, and potential risks. Environ Sci Pollut Res 20:5150-5159

Zhao L, Hou H, Zhou Y, Xue N, Li H, Li F (2010) Distribution and ecological risk of polychlorinated biphenyls and organochlorine 
pesticides in surficial sediments from Haihe River and Haihe Estuary Area, China. Chemosphere 78:1285-1293

Zheng X, Chen D, Liu X, Zhou Q, Liu Y, Yang W, Jiang G (2010) Spatial and seasonal variations of organochlorine compounds in air on an urban-rural transect across Tianjin, China. Chemosphere 78:92-98
Zhou JL, Maskaoui K, Qiu YW, Hong HS, Wang ZD (2001) Polychlorinated biphenyl congeners and organochlorine insecticides in the water column and sediments of Daya Bay. China Environ Pollut 113:373-384 